\title{
Philosophers of Process
}





\section{PHILOSOPHERS of PROCESS}

edited by

Douglas Browning and

William T. MYers

FORDHAM UNIVERSITY PRESS

New York • 1998 
Copyright (C) 1998 by Fordham University Press

All rights reserved

LC 98-25568

ISBN 0-8232-1878-3 (hardcover)

ISBN 0-8232-1879-1 (paperback)

Library of Congress Cataloging-in-Publication Data

Philosophers of process / edited by Douglas Browning and William T. Myers. - 2nd ed.

p. $\mathrm{cm}$.

Includes bibliographical references.

ISBN 0-8232-1878-3 (hc.). - ISBN 0-8232-1879-1 (pbk.)

1. Process philosophy. 2. Philosophers, Modern-United States. 3. Philosphers, Modern-Europe. I. Browning, Douglas, 1929_ . II. Myers, William T.

BD372.P54 1998

$146^{\prime} .7-\mathrm{dc} 21$

98-25568

CIP

Printed in the United States of America 